that which many inventors have followed when dealing with the work of rivals; in doing so, he has added--if that be possible - to the high reputation which he had previously acquired as an engineer.

W. H. W.

\section{INFERIOR RACES.}

The Mind of Primitive Man. By Franz Boas. A Course of Lectures delivered before the Lowell Institute, Boston, Mass., and the National University of Mexico, I9ro-II. Pp. xi+294. New York : The Macmillan Co. ; London : Macmillan and Co., Ltd., I9Ix.) Price $6 s$. $6 d$. net. FAMOUS psychological novelist has asserted that even when love unites two members of distinct races their life, however harmonious, is lived over a slumbering volcano of hate. There is a popular fallacy that racial antipathy is based on physiological foundations. But in so far as such antipathy is real, there is nothing physiological in its causation; and its emotional strength depends on the law that the more automatic and unconscious a habit is, the greater is the displeasure felt and the disgust aroused by infractions of the habit. The most plausible form of this racial habit is one which even scientifically trained minds find it difficult to transcend. This is the attitude of superiority consciously or unconsciously adopted by civilised men towards the semicivilised, and among the civilised by the so-called Caucasian race. As Prof. Boas puts it, "Proud of his wonderful achievements civilised man looks down upon the humbler members of mankind." The European looks down on the civilised Oriental. The point of interest, however, is that he claims to be of a higher type, possibly physical, but certainly psychical, on the assumption that achievement depends solely upon aptitude for achievement.

In these lectures, delivered before the Lowell Institute and the National University of Mexico, the main thread of Prof. Boas's argument is that this assumption and this claim of superiority of type are unproven. In support of his argument he employs data from the whole field both of physical and of social anthropology, and the resulting exposition of the salient features of difference between the civilised and the primitive types of man has the advantage of the author's first-hand experience and personal investigation.

He notes that the ancient civilisation of the Old World, not essentially superior to that of the New, reached its height 3000 years earlier for accidental reasons. He explains the European aptness for civilisation as not necessarily due to No. 2216 , VOL. 89] superior faculty. Due regard is had to heredity and environment, and several confusions of thought on the subject are cleared up. In reference to environment, his own remarkable observations are introduced, namely, that the American-born children of European immigrants (European-born) respond at once in a curious way. The short, darkhaired, and longheaded Sicilian loses in stature; the head increases in width and loses in length, becoming brachycephalic. The medium-sized, short-headed native of Central Europe gains in stature and in narrowness of head. The tall, long-headed European of the north-west grows taller.

The observation made by Fritsch on the Bushman is applied generally to man. Europeans, for instance, are to savages as domesticated animals are to wild. Their bones, that is, become, though heavier, less solid and less slender; their structure is more open. The mental change in domesticated animals is undoubted. Modifications of type, physical and mental, he concludes, are largely due to the progressive domestication of man incidental to the advance of civilisation.

The author's discussion and explanation of the causes and results of variation within a race, brief though they are, supply the most convincing theory that has yet appeared. The whole question of permanence and variation of type, in fact, is trcated in a masterly way.

The ordinary view of the mental deficiencies of the "inferior races" is remorselessly criticised. The lowest savage does possess self-control. He is not improvident, but rather optimistic. He can concentrate his mind. He possesses originality. Savages who do not count beyond three or ten easily adapt their language and intellect to civilised methods of reckoning. The same is the case with abstract and general ideas, as Prof. Boas has himself proved by experiment. The point is that these civilised methods are not needed in the primitive state, where each man on a warexpedition is known by name, though the number of the troop may not be reckoned.

Both in mind and in body there is little to choose between the ordinary barbarian and civilised man. The thesis is applied to a practical purpose in the last lecture, the question of the influence of the negro and of the European immigrant upon the type of the American citizen. No one interested in this or in other racial questions can afford to pass over this most sane and scientific critique. The whole volume is conspicuous both for balanced reasoning and for brilliance, and as a practical application of anthropology is of the first importance.

A. E. Crawley. 